\title{
Low-Level Aerial Photography as a Manage- ment and Research Tool for Range Inventory
}

\author{
T.W. HEINTZ, J.K. LEWIS, AND S.S. WALLER
}

\begin{abstract}
An inexpensive technique is reviewed for using low-level aerial photography as a management and research tool for range. Modifications of a previously documented camera mount are reported that allow greater flexibility in the use of aerial photography for range evaluation. This technique involves the use of color infrared film with a $135-\mathrm{mm}$ telephoto lens double filtered with orange and magenta filters.
\end{abstract}

As increasing demands are placed on our private and public rangelands, care must be taken to manage these valuable resources in such a way as to maintain them in a productive condition. To manage rangelands properly. records of annual vegetative changes should be maintained and evaluated. Vegetation samples are usually clipped to provide records for documenting changes in vegetation. This requires a substantial anrount of labor. time, and money. Collecting information about changes in vegetation utilizing low-level aerial photography can reduce time. labor, and expense.

Aerial photographs from a light plane can be obtained rapidly with a minimum amount of labor. These photographs contain valuable information that can be used for managing private and public lands, and for range research purposes. Many agencies already have the necessary equipment at their disposal for collecting aerial photographs. The Bureau of Land Management in Montana has used a $35-\mathrm{mm}$ aerial photography system for several years (Meyer and Gerbig 1974). This method of data collection enabled them to inventory study plots more rapidly than from the ground. Small format $(35-\mathrm{mm})$ aerial photography from light aircraft has great potential as part of a coordinated system of range inventory. Aerial photographs of the same area at different times during the year and from year to year can provide information on patterns of growth and utilization of range vegetation, vegetative change, range condition. and occurrence of biotic disturbance as well as an overall view of the area.

Tubors are rescarch technician. associate professor. and assistant protensor, respec Anmal Science Department. South Dahota State University. Brookings. S.D

11. Heint is currently employed as a range conservationist w ith the Forest Service 11 Wadom. Montana. and S.S. Waller is presently associate professor. Department of Igromomy. L niversity of Nebraska. Lincoln NE ox583.

Ihus repert is approsed for publication by the Director of South Dahota Agricultural periment Station as Publication No. 1560 of the Journal Series

Ific atuthor exend their appreciation to Roy V. Muchow. South Dahota State ancerly theincering shop, for the design and construction of the camera mount used in studis

Vhameript recenced April 24.1978.

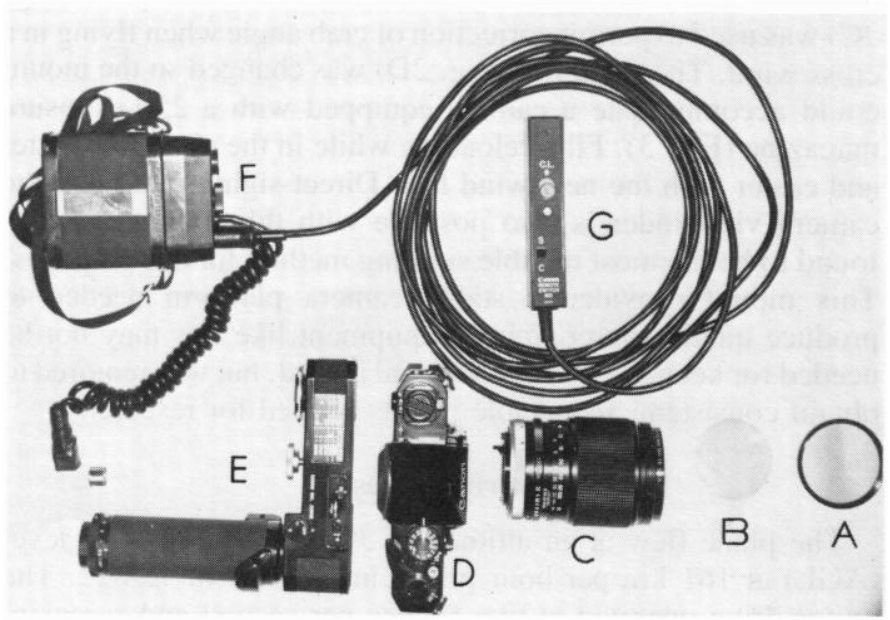

Fig. 1. Camera set up with a Tiffen 15 orange filter (A), Kodak magenta filter (B). Canon $135 \mathrm{~mm}$ telephoto lens $(C)$, Canon $F-1$ (D), Canon motor drive $(E)$, Canon power pack $(F)$ with remote switch $(G)$.

Part of the range research at South Dakota State University uses low-level aerial photography to obtain high-quality infrared stereograms in $35-\mathrm{mm}$ format. These pictures are used for determining sample collection programs and maintaining a pictorial record of vegetation on experimental ranges at the Range and Livestock Experiment Station. Cottonwood. South Dakota.

\section{Equipment}

Photographs were collected using a $35-\mathrm{mm} \mathrm{Canon}^{1} \mathrm{~F}-\mathrm{I}$ camera equipped with a motor drive and a $135-\mathrm{mm}$ telephoto liltered with Tiffen 15 orange and Kodak magenta filters (Fig. 1). A camera mount using the same basic design of Meyer (1973) was built by university personnel to fit light. high-wing aircraft (Fig. 2). Various modifications were nade to improve the mount. The base unit (Fig. 2B), which fastens to the door of the plane. was modified to make the mount usable on tandem aircraft with conventional landing gear that can operate from

Mention of product names in this paper does not comstitute a recommendation by the south 1)ahotat Agricultual teperiment Station. 
tion throughout the growing season could be more easily documented. Live vegetation appeared as shades of red and dead plant material as shades of green when color infrared pictures were taken with the orange and magenta filters.

The color infrared film was processed in a field laboratory at the Range and Livestock Experiment Station. This was accomplished by converting part of the laboratory into a darkroom. using a controlled-temperature waterbath. Kodak E-4 color processing kits. Kodak color control processing strips, and Durst developing equipment. Film was removed from the film cartridge within a Burke and James changing bag and put into a light-tight developing canister. eliminating the need for a total darkroom. Actual processing time in the developing tank was 55 minutes. The total procedure required about 70 minutes, including time for getting the film onto the reels and into the developing tank, developing the film. wiping the film. and hanging it up to dry. The result was high-quality imagery that enibited remarkable detail.

Fig. 2. Camera with 36-exposure magazine (A) attached to the camera mount The camera mount attaches to the door of the airplane with the window in the up position by a cushioned clamp base unit $(B)$. I Note the center pivot-point (C) and the wind foil (D)).

rough or nonexistent landing fields. A center pivot-point (Fig. C) was used to permit correction of crab angle when flying in a cross wind. The wind foil (Fig. 2D) was changed so the mount could accommodate a camera equipped with a 250-exposure magazine (Fig. 3). Film reloading while in the air is also faster and easier with the new wind foil. Direct-sighting through the camera viewfinder is also possible with this mount and was found to be the most reliable sighting method for our purposes. This mount provided a stable camera platform needed to produce quality stereograms. Equipment like this may not be needed for keeping a yearly pictorial record, but was required to obtain consistent, repeatable results needed for research.

\section{Procedures}

The plane flew at an altitude of $381 \mathrm{~m}$ above ground level (AGL) at $161 \mathrm{~km}$ per hour producing a scale of $1: 2822$. The motor drive operated at two frames per second and a camera shutter speed of $1 / 500$ second was used. This provided approximately $50 \%$ overlap of consecutive frames for stereo coverage. Color infrared Ektachrome film was used. with a combination of both Tiffen 15 orange and Kodak magenta filters attached to the lens.

Color infrared film was used because it provided more information than color Ektachrome. Living vegetation was easily distinguished on the infrared film and changes in vegeta-

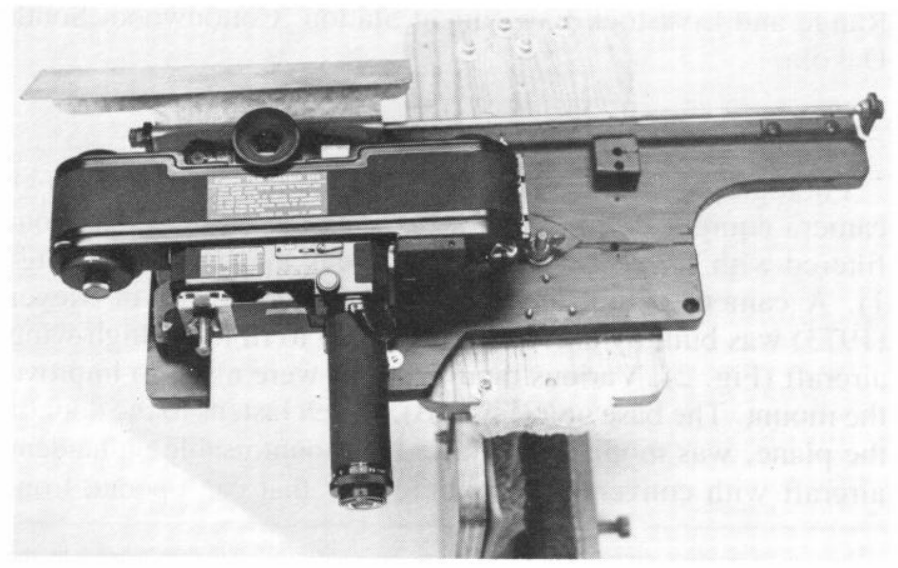

Fig. 3. Camera with a 250-exposure magasine attached to the camera mount.

Problems encountered with this method of data collection are many and varied. but can be solved with experience and practice. The weather in South Dakota is especially unpredictable. One can never pick a day in advance to take pictures from a light aircraft. Cloud conditions are often quite variable. and winds are often too gusty for a small plane to tly in a precise line. Consequently, a pilot and airplane with a flexible schedule are needed.

Reliable camera equipment is a necessity. A dependable yystem that gives consistent results is required, particularly in research work. Valuable time and money may be lost if inferior equipment is used. Thus, the most economical camera for such a job may be one of the more expensive, but highly dependable. models.

Color infrared film was available only in twenty exposure rolls making reloading film while in the air a necessity in our operation. This presented certain hazards. When the camera was in the operating position outside the plane, it was buffeted by a substantial blast of air. Thus, a camera mount that allowed the camera to be brought inside the airplane was needed for removing and loading film. Empty and loose film canisters rolling around the floor of the plane also made it difficult to maintain an organized process. This problem was solved by laping film canisters together into a belt and numbering them. The lens was taped at infinity to prevent it from being accidentally turned out of focus.

The major problem encountered in flying relatively low-level acrial photography in a light plane was marking the area so that it could be seen easily from the air and then lining up and staying on the flight line to achieve accurate, repeatable coverage. This problem was solved by marking the flight lines with white planks and numbering them with formations of white painted rocks. The rock formations were $1.83 \mathrm{~m}$ in length and planks were $3.05-3.66 \mathrm{~m}$ long and $25.4 \mathrm{~cm}$ wide. The white markers stood out well and were easy to see from a distance (Fig. 4).

In order to stay on the flight lines, the photographer leaned out of the airplane and looked through the camera viewfinder. This gave the photographer the opportunity to check the camera setting immediately before shooting and to start the motor drive at the proper time. This also gave the photographer the option of not shooting if the plane was not properly lined up, or if it was blown off target at the last minute. A periscope was constructed which was mounted on the camera mount and allowed the 
